\title{
APPLiCATION OF TwO-STAGE MCDM TeChniques in Evaluating THe Performance of Electronic Payment Systems in GHaNa
}

\author{
Dennis Asante, Evans Opoku-Mensah and Peter Adjei Darko \\ School of Management and Economics, \\ University of Electronic Science and Technology of China, Chengdu, China
}

\begin{abstract}
Electronic payment systems act as a catalyst in the economic development of many developing countries. However, their evaluation has become a daunting task over the years. This research employed a two-stage multi-criteria decision analysis (MCDA) to evaluate e-payment systems in Ghana. The AHP method was utilized to find the contribution scores of the various criteria for the performance of the e-payment systems. With the aid of the Probability Linguistic-TOPSIS (PL-TOPSIS) approach, we obtained the performance scores of the e-payment systems and ranked them. Among the six indicators employed in this study, we found cost-effectiveness to be the major indicator of an e-payment system performance. The performance ranking results indicated that credit/debit card has the highest performance score, followed by mobile money, ATM, online banking, and E-zwitch, respectively. We contribute to literature by providing intuitions on how AHP and PL-TOPSIS methods can be applied to evaluate the performance of e-payment systems.
\end{abstract}

\section{KEYWORDS}

Electronic payment systems, Analytic Hierarchy process, Probabilistic linguistic-TOPSIS, Multi-criteria decision making analysis

\section{INTRODUCTION}

Financial services industry and other economic transaction firms have undergone various stages of technological evolutionary developments [1]. These establishments over the years have succumbed to operational transformation known as e-development. Payment systems have a significant effect on a country's fiscal policy and by extension on her economic development [2]. The cash-based payment system is rather giving way to electronic payments (e-payments) in modern businesses [3][4]. E-payment systems have taken the centre stage in ensuring innovation and efficiency in the world payment system by bringing to bear fraud reduction [5]. The effectiveness of e-payment system to accelerate economic development as shown by available literature [2][6], has contributed to its steady adoption in many developing countries such as Ghana.

The payment system in Ghana has undergone a substantial improvement over the past decade. The country's payment landscape has been shaped by her developments in national economic infrastructure such as the rapid installation of Automated Teller Machine (ATMs), steady penetration of internet and availability of Global System for Mobile Communication (GSM) technology. To optimize the operations of financial institutions to reap the economic benefits of e-payment systems, Government of Ghana (GOG) has instituted policy framework to oversee the

+ Authors contributed equally to this work. 
Implementation of these payment systems. Again, Ghanaian public sector workers are gradually being moved onto the biometric e-zwich payment platform. Despite these policy interventions and rapid strengthening of infrastructure baseline to transform Ghana into a cash-lite economy, scientific evaluation of the performance of these payment channels remains unsatisfactory. Existing studies conducted on e-payment development in the country either focused on the trajectory of the system [7], factors affecting their adoption [8]-[11] or challenges of their implementation [10][12]. A holistic evaluation of the e-payment channels available in the Ghanaian economy will be a prerequisite to inform the allocation of resources strategically, redirect policy, and ignite healthy competition within the financial sector.

Currently, performance evaluation is too complex to be realized through examination of onedimensional approach [13]. A more appealing evaluation approach would be the synchronized consideration of all relevant factors that are related to the evaluation problem. Multi-criteria Decision Analysis (MCDA) affords such a framework, together with diversity of sophisticated operational tools that are geared towards the support of the decision makers in facing real-world decision problems. MCDA is a vital mental and reasoning process in the life of human beings, which leads to the evaluation and selection of the best alternative(s) [14]. MCDA has been concerned with structuring and solving decisions, planning, and evaluating problems involving multiple criteria [15]. In evaluating e-payment systems in Ghana, decision-makers may find it difficult to precisely select a preference regarding alternatives under several criteria, especially when relying on inaccurate, uncertain or incomplete information [14][16]. This paper, therefore, employs the fuzzy set theory proposed by Zadeh [17] into MCDA method to aid in overcoming these problems of uncertainty and incomplete information to evaluate the performance of epayment systems in Ghana. We focus on ATM, Mobile money, E-Zwich, Mobile banking, and credit/debit cards. We evaluate these e-payment systems mainly due to their prominence in the Ghanaian business landscape and partly due to the government's commitment to developing infrastructure for these electronic payment channels to thrive. Specifically, the evaluation of these electronic payment outlets is carried out by using the Analytical Hierarchy Process (AHP) [18] mechanism and probabilistic linguistic fuzzy TOPSIS approach developed by [19].

The remaining part of this paper is organized as follows. The next section presents the literature related to the topic of this study. The methodology adopted is described next. The data collected are analyzed and discussed. The paper then concluded with the results implications, recommendations, and future directions.

\section{LITERATURE REVIEW}

\subsection{E-Payment Systems in Ghana}

In Ghana, there exist at least 5 e-payment systems. These include mobile money, online banking, e-zwich, credit/ debit card, ATM [20]. Mobile money describes electronic financial services performed via a mobile phone. According to Mubarik [21], mobile money transactions in Ghana reached a total of 679.17 million Ghana cedis as at mid-June 2016. This figure represented a $20 \%$ growth compared to the 547.96 million Ghana cedis recorded for the period 2015. Mobile money services can contribute to local development by making money transfers faster, safer, and more convenient as well as lowering the cost of transactions.

E-zwich, the brand name for biometric switch and smart card payment, which was introduced by banks in Ghana in 2008, recorded a value of 3.8 million Ghanaced is in the first year. According to GhIPSS [22], total transactions recorded by E zwich reached an estimated value of 174 billion Ghanaced is as of 2016. This growth is an indication of a significant drop in cash transactions 
[22]. Online Banking is the use of internet technologies to render services to their customers without the presence of brick-and-mortar interactions between the customer and bank employees [23]. Ghana's online banking has improved due to the expansion of internet coverage to the hinterlands through government initiatives with the help of international partners. Despite 27.8 percent of the population being internet users, the patronage of online banking is low [24]. Online banking is noted for its cost-effectiveness and convenience [25]. Notwithstanding these benefits, customers of Ghanaian banks have concerns about their security and safety measures [26]. ATMs have become the face of many financial institutions [27]. For many consumers, ATMs are the only interaction they have with their banks. In addition, ATMs are also becoming a competitive mark for many banks. Credit cards play a vital role in global finance and credit systems [28]. It is a convenient form of payment throughout the world, allowing consumers freedom from cash as well as allowing deferred payment for goods and services [29]. In many developing countries, such as Ghana, credit card usage is very limited, even though people have heard about its usage [30]. Debit cards are expected to be in use in places where most transactions are done by cash or cheque in supermarkets, petrol stations, convenience stores. These types of cards are ideal for those who have a tight budget and want to keep within it.

\subsection{Evaluation of E-Payment Systems Using MCDM}

Many studies have used several methods in evaluating e-payment systems. Some of these methods include statistical techniques, data envelopment analysis (DEA), MCDM analysis etc. Although different models have been proposed to evaluate the e-payment systems performance, most of them have either limited application or evaluate different dimensions of the performance. Statistical techniques and other evaluation models have focused more on the structural elements or inputs, some of them on the process evaluation and other on the results. However, there are few that look at the comprehensive inclusion of the balanced evaluation of inputs, processes and outputs. Unlike the DEA, the MCDM analysis is more robust in examining the balanced evaluation of e-payment systems. MCDM analysis assists decision makers to model complex conflicting factors during the evaluation process.

Making decisions involve choosing from a set of alternatives [13][31]. Customer faces the challenge of choosing the best payment method out of the numerous options available. Since making such a decision involves a lot of multiple criteria, it can be modeled as MCDM [13]. MCDM helps to rank the various e-payment systems according to their performance. Moreover, it brings to light how e-payment users rank the performance of various criteria. Various authors have used different MCDM approaches in different situations. While some use the MCDM approach to rank various criteria, others use MCDM to rank service providers in various industries. For instance, Zokaee et al. [31] using the analytic hierarchy process (AHP) method found debit and credit cards to be the most preferred e-payment channel, followed by credit cards, electronic cheques, charging cards and electronic money in Iran. Another study by Osmani et al. [32] employed AHP and constructed four criteria and twenty-two sub-criteria to examine the factors that impact mobile banking usage in the Iranian banks. They found security infrastructure to be the most significant factor that influences the use of mobile banking in Iran. Using the fuzzy multi-criteria decision to assess e-payment systems in Turkey, Alptekin and Alptekin [33] found that the preferable payment system varies with the perspective of the decision maker. Studying the factors that influence customer's decision to use a particular internet banking system in Taiwan, $\mathrm{Hu}$ and Liao [34] found that the criteria that are of greater concern to customers are efficiency, reliability, continuous improvement and tangibility. The degrees of importance of respective aspects provide a general view of evaluating the electronic service quality. Based on the literature reviewed, we selected reliability, ease of use, usefulness, responsiveness, security, and cost-effectiveness as the criteria use in this paper. 
Reliability is interpreted as the ability of a system to perform its function with accuracy and execute the service promised [35]. To be considered reliable, the e-payment system needs to function just as it has been stated to do especially in terms of accuracy, consistency and also available within the promised time frame to the satisfaction of consumers. Ease of use is defined as "the extent to which a person believes that using a particular system will be free from effort" [36][37]. Paying with an electronic payment system should not be a complex task and a burden for users. Payments should be devoid of interruptions and should be automated. Moreover, the interface of the system should be easy to be operated. Usefulness of an e-payment system is the degree to which a person is benefited from the use of a particular payment system [38]. Thus, the level at which users of an e-payment system believes that the use of the system will enhance their productivity. The usefulness of a payment system depends on the type of transactions it can serve. The types of transactions a payment system can serve however vary from country to country and even regions in the country, depending on the rules that operate within the place. Responsiveness could be explained as the effective handling of customers' problems and concerns [34]. thus, how timely customers e-mail requests or complaints, and confirmations of orders are responded and are attended to. It is technically easier to send customers automatic response, acknowledging the receipt of customers' emails complained and suggestions [39]. However, responsiveness goes beyond just an automatic response but rather providing a solution to complains and listening to customers suggestions. Security of an e-payment system can be explained as the ability of the system to assure customers that no-one else can divert a payment or impersonate another person in order to steal funds [40]. Worku [41] observed that for effective e-payment implementation, it is crucial to understand and address security concerns in order to leverage the potential of ICTs in delivering e-banking applications. Every user should be protected from a collision or other. Barkhordari et al. [2] found that both perceived security and trust have positive impact on using epayment systems. Cost-effectiveness is the ability of customers to enjoy minimal cost on the value of the transaction [37]. Osmani et al. [32] concluded that customers will be less likely to make any transaction if the transaction cost is high. Low transaction cost must be ensured in any means to retain the customers.

\section{METHOD}

Multiple-criteria decision method (MCDM) is mainly concerned with developing mathematical and computational tools to aid the subjective assessment of a finite number of decision alternatives under a finite number of performance criteria by a single decision maker or by a group [42][43]. MCDM focuses primarily on structuring and solving decision and planning problems involving multiple criteria [44]. Therefore, the components of MCDM include a set of alternatives, a set of criteria, and evaluation values. The evaluation procedure in this paper consists of three main steps:

1. Identify the main e-payment systems available in Ghana and the evaluation criteria considered as the most important performance measures.

2. Construct the hierarchy of the evaluation criteria and calculate the weights of these criteria using the AHP technique.

3. Utilize the fuzzy TOPSIS method to achieve the final performance and ranking results.

In order to evaluate the performance of e-payment systems in Ghana, this paper adopts the AHP technique and probabilistic linguistic extended TOPSIS method developed by [19]. The detailed descriptions of each step are illustrated in the following subsections. 


\subsection{Identification of E-Payment Systems and Evaluation Criteria}

In this paper, the set of alternatives comprise the various payment systems under evaluation: ATM, Mobile Money, Online Banking, E-Zwitch, and Debit (Credit) card. These alternatives are evaluated based on the following criteria extracted from literature: Reliability, Ease of use, Responsiveness, Security, Cost, and Usefulness [31][32][34][37].

\subsection{Analytic Hierarchy Process (Ahp)}

The Analytic Hierarchy Process (AHP) [18] is a multi-criteria decision analysis method proposed by Thomas L. Saaty in 1980. The AHP provides a framework that aids decision-makers to model a complex problem in a hierarchical structure for prioritizing alternatives in order to determine the optimal alternative using pair-wise comparison judgments [45]. The hierarchy shows the relationships of the goal, objectives (criteria), and alternatives. AHP is composed of a hierarchical structure of complexity, pairwise comparisons, judgments with respect to goal and criteria, an eigenvector method for obtaining weights, and consistency calculation. AHP technique subdivides a complex decision-making problem into easily understandable hierarchy elements and makes decisions based on the elements which convert qualitative factors into a quantitative variable [13]. In order to compare the relative importance of element at each stage, a pairwise comparison matrix is constructed using the Saaty 1-9 preference scale, as illustrated in Table 1.

Table 1. Saaty's pairwise comparison scale

\begin{tabular}{l|l}
\hline Scale & Compare factor of $i$ and $j$ \\
\hline 1 & Equally Important \\
3 & Weakly Important \\
5 & Strongly Important \\
7 & Very Strongly Important \\
9 & Extremely Important \\
$2,4,6,8$ & Immediate value between adjacent scales \\
\hline
\end{tabular}

Then the eigenvector and maximum eigenvalue $\lambda_{\max }$ are computed from the pairwise comparison matrix. The importance of the eigenvalue is to evaluate the strength of the consistency ratio [46] of the comparative matrix. The CR assists to validate whether the pairwise comparison provides a suitable consistent evaluation. The detailed procedure of AHP is presented as follows [47].

1. Structure the problem into hierarchy considering the objective of the decision, while the data are collected from experts or decision-makers corresponding to the structure.

2. Construct the pairwise comparison matrix. Assuming $n$ attributes, the pairwise comparison of the attribute $i$ with attribute $j$ yields a square matrix $A_{n x n}$ where $a_{i j}$ denotes the comparative importance of attribute $i$ with respect to attribute $j$. In the matrix,

$$
a_{i j}=1 \text { When } i=j \text { and } a_{j i}=\frac{1}{a_{i j}} \text {. }
$$


International Journal of Data Mining \& Knowledge Management Process (IJDKP) Vol.9, No.2/3, May 2019

$$
A_{n x n}=\begin{aligned}
& 2\left[\begin{array}{llll}
a_{11} & a_{12} & \mathrm{~L} & a_{1 n} \\
a_{21} & a_{22} & \mathrm{~L} & a_{2 n} \\
\mathrm{M} & \mathrm{M} & \mathrm{M} & \mathrm{M} \\
a_{n 1} & a_{n 2} & \mathrm{~L} & a_{n n}
\end{array}\right]
\end{aligned}
$$

3. Construct a normalized decision matrix $c_{i j}$ by using the following equation:

$$
c_{i j}=\frac{a_{i j}}{\sum_{i=1}^{n} a_{i j}}, i=1,2, \ldots, n ; j=1,2, \ldots, n
$$

4. Construct the weighted normalized decision matrix as:

$$
\begin{gathered}
w_{i}=\frac{\sum_{j=1}^{n} c_{i j}}{n}, i=1,2, \ldots, n \\
w=\left[\begin{array}{c}
w_{1} \\
w_{2} \\
\mathrm{M} \\
w_{n}
\end{array}\right]
\end{gathered}
$$

5. Calculate Eigenvector and Row matrix by:

$$
\begin{array}{r}
E=\frac{N^{\text {th }} \text { rootvalue }}{\sum N^{\text {th }} \text { rootvalue }} \\
\text { Rowmatrix }=\sum_{j-1}^{n} a_{i j} * e_{j 1}
\end{array}
$$

6. Calculate the maximum Eigenvalue, $\lambda_{\max }$

$$
\lambda_{\max }=\frac{\text { Rowmatrix }}{E}
$$

7. Calculate the consistency index and consistency ratio.

$$
\begin{aligned}
& C I=\frac{\left(\lambda_{\max }-n\right)}{n-1} \\
& C R=\frac{C I}{R I}
\end{aligned}
$$


where, $n$ and $R I$ denote the order of matrix and Randomly Generated Consistency Index, respectively. A consistency ratio (CR) value of $10 \%$ or less is considered acceptable; otherwise, the pairwise comparisons should be revised [13].

\subsection{Probabilistic Linguistic-TOPSIS}

For the performance evaluation of e-payment systems in Ghana, one of the MCDM methods, probabilistic linguistic-TOPSIS has been applied in this research. TOPSIS (Technique for Order Preference by Similarity to Ideal Solution), developed by Yoon and Hwang [48] is one of the MCDM methods for resolving real-world decision problems satisfactorily. TOPSIS attempts to indicate the best alternative that simultaneously has the shortest distance from the positive ideal solution and the farthest distance from the negative ideal solution [49]. The positive ideal solution is a solution that tries to maximize the profit criteria and minimize the cost criteria, whereas the negative ideal solution is just opposite to the previous one [15][50][51]. The detailed algorithm of the probabilistic linguistic-TOPSIS based on [52] is outlined as follows:

Step 1: Based on the practical decision-making problem, we let $x=\left\{x_{1}, x_{2}, \ldots, x_{m}\right\}$ be a finite set of $m$ alternatives, and $c=\left\{c_{1}, c_{2}, \ldots, c_{n}\right\}$ be a set of $n$ criteria, whose weight vector is given as $w=\left\{w_{1}, w_{2}, \ldots, w_{m}\right\}^{T}$. Then, the decision makers provide their evaluation values respectively, which can be expressed by a probabilistic linguistic set (PLTS): $L_{i j}(p)=\left\{L_{i j}^{(k)}\left(p_{i j}^{(k)}\right) \mid k=1,2, \ldots, \# L_{i j}(p)\right\}$, where $L_{i j}^{(k)}$ is the $k t h$ value of $L_{i j}(p)$ and $\left(p_{i j}^{(k)}\right)$ is the probability of $L_{i j}^{(k)}, \quad\left(p_{i j}^{(k)}\right)>0, k=1,2, \ldots, \# L_{i j}(p), \sum_{k=1}^{\# L_{i j}(p)} p_{i j}^{(k)}=1$ and $\# L_{i j}(p)$ is the number of linguistic terms in $L_{i j}(p)$. The PLTS denotes the evaluation of the alternatives $x_{i}(i=1,2, \ldots, m)$ with respect to the criteria $c_{j}(i=1,2, \ldots, n)$ by using the linguistic evaluation scale $S=\left\{s_{a} \mid a=0,1, \ldots, t\right\}$. Then, all the PLTSs are contained in the probabilistic linguistic decision matrix $R=\left[L_{i j}(p)\right]_{m \times n}$ of Table 2 .

Table 2. Probabilistic linguistic decision matrix $R$

\begin{tabular}{|l|l|l|l|l|}
\hline & $c_{1}$ & $c_{2}$ & $\mathbf{L}$ & $c_{n}$ \\
\hline$x_{1}$ & $L_{11}(p)$ & $L_{12}(p)$ & $\mathbf{L}$ & $L_{1 n}(p)$ \\
\hline$x_{2}$ & $L_{21}(p)$ & $L_{22}(p)$ & $\mathbf{L}$ & $L_{2 n}(p)$ \\
\hline $\mathrm{N}$ & $\mathrm{N}$ & $\mathrm{N}$ & $\mathrm{N}$ & $\mathrm{N}$ \\
\hline$x_{m}$ & $L_{m 1}(p)$ & $L_{m 2}(p)$ & $\mathbf{L}$ & $L_{m n}(p)$ \\
\hline
\end{tabular}

Step 2: Transform the given probabilistic linguistic decision matrix $R=\left[L_{i j}(p)\right]_{m \times n}$ into the normalized probabilistic linguistic decision matrix $\boldsymbol{R}=\left[L_{i j}(\not)\right]_{m x n}$. Given a PLTS $L(p)$ with $\sum_{k=1}^{\# L_{L_{i}}(p)} p^{(k)}<1$, then the transformation of $L(p)$ into $\$(p)$ is given as: 


$$
\begin{aligned}
& \oint_{i j}(p)=\left\{L_{i j}^{(k)}\left(\mu^{(k)}\right) \mid k=1,2, \ldots, \# L_{i j}(p)\right\}, \\
& \text { Where } \mu^{\mu^{(k)}}=\frac{p^{(k)}}{\sum_{k=1}^{\# L(p)} p^{(k)}}, k=1,2, \ldots, \# L(p) .
\end{aligned}
$$

Step 3: Given the normalized probabilistic linguistic decision matrix, $\boldsymbol{R}=\left[L_{i j}\left(\mu^{\prime}\right)\right]_{m x n}$ we determine the positive-ideal solution (PIS) and negative-ideal solution (NIS). The PIS of alternatives based on the probabilistic linguistic decision matrix $\hat{R}$ is given as:

$$
\left.\left.\left.\S(p)^{+}=\left(L_{1}(\not)^{\top}\right)^{+}, L_{2}(\not)^{\top}\right)^{+}, \ldots, L_{n}(\not)^{\top}\right)^{+}\right)
$$

where $\$(p)^{+}=\left\{\left(L_{j}^{(k)}\right)^{+} \mid k=1,2, \ldots, \# L_{i j}(p)\right\}=\left\{\left(L_{j}^{(1)}\right)^{+},\left(L_{j}^{(2)}\right)^{+}, \ldots,\left(L_{j}^{\left(\# b_{i j}\right)}\right)^{+}\right\}$,

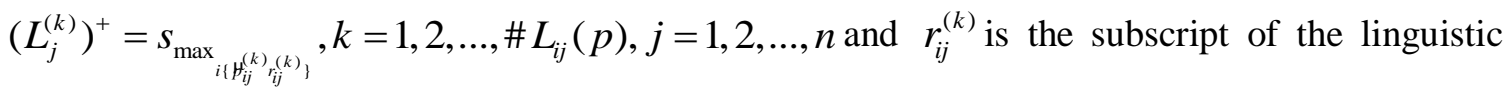
$\operatorname{term} L_{i j}^{(k)}$.

Analogously, the NIS of the alternatives can also be determined as follows:

$$
\$(p)^{-}=\left(L_{1}(\not)^{-}, L_{2}(\not)^{-}, \ldots, L_{n}(\not)^{-}\right),
$$

where $\$(p)^{-}=\left\{\left(L_{j}^{(k)}\right)^{-} \mid k=1,2, \ldots, \# L_{i j}(p)\right\}=\left\{\left(L_{j}^{(1)}\right)^{-},\left(L_{j}^{(2)}\right)^{-}, \ldots,\left(L_{j}^{\left(\# b_{i j}\right)}\right)^{-}\right\}$, $\left(L_{j}^{(k)}\right)^{-}=s_{\min _{i\left(\left.\right|_{i j} ^{(k)} r_{i j}^{(k)}\right)}}, k=1,2, \ldots, \# L_{i j}(p), j=1,2, \ldots, n$ and $r_{i j}^{(k)}$ is the subscript of the linguistic term $L_{i j}^{(k)}$.

Step 4: We then calculate the deviation degrees between each alternative and the PIS as:

$$
\begin{aligned}
d\left(x_{i}, \$(p)^{+}\right)=\sum_{j=1}^{n} w_{j} d\left(\Phi_{i j}(p)\right. & \left., \Phi_{j}(p)^{+}\right) \\
= & \sum_{j=1}^{n} w_{j} \sqrt{\frac{1}{\# L_{i j}(p)} \sum_{k=1}^{\# L_{i j}(p)}\left(\mu_{i j}^{(k)} r_{i j}^{(k)}-\left(p_{i j}^{(k)} r_{i j}^{(k)}\right)^{+}\right)^{2}} .
\end{aligned}
$$

Obviously, the smaller the distance $d\left(x_{i}, \$(p)^{+}\right)$, the better the alternative $x_{i}$.

Likewise, the deviation degree between each alternative and the NIS can be calculated as:

$$
d\left(x_{i}, \$(p)^{-}\right)=\sum_{j=1}^{n} w_{j} d\left(\$_{i j}(p), \$_{j}(p)^{-}\right)
$$




$$
=\sum_{j=1}^{n} w_{j} \sqrt{\frac{1}{\# L_{i j}(p)} \sum_{k=1}^{\# L_{i j}(p)}\left(p_{i j}^{(k)} r_{i j}^{(k)}-\left(p_{i j}^{(k)} r_{i j}^{(k)}\right)^{-}\right)^{2}}
$$

and the larger the distance $d\left(x_{i}, \$(p)^{-}\right)$, the better the alternative $x_{i}$.

Step 5: Finally, we compute the closeness coefficient $C I$ to obtain the performance score of each alternative and then rank them. The $C I$ is computed as:

$$
C I\left(x_{i}\right)=\frac{d\left(x_{i}, \$(p)^{-}\right)}{d_{\text {max }}\left(x_{i}, \$(p)^{-}\right)}-\frac{d\left(x_{i}, \$(p)^{+}\right)}{d_{\text {min }}\left(x_{i}, \$(p)^{+}\right)},
$$

Where

$$
\begin{aligned}
d_{\max }\left(x_{i}, \$(p)^{-}\right) & =\max _{1 \leq i \leq m} d\left(x_{i}, \$(p)^{-}\right) \\
& d_{\text {min }}\left(x_{i}, \$(p)^{+}\right)=\min _{1 \leq i \leq m} d\left(x_{i}, \$(p)^{+}\right)
\end{aligned}
$$

and $C I\left(x_{i}\right) \leq 0(i=1,2, \ldots, m)$. It should be noted that the larger the closeness coefficient $C I\left(x_{i}\right)$, the better the alternative $x_{i}$. Hence, the best alternative

$$
x^{*}=\left\{x_{i} \mid \max _{1 \leq i \leq m} C I\left(x_{i}\right)\right\}
$$

Can be selected.

\section{Evaluation of E-Payment Systems Performance}

\subsection{Sampling and Data Collection}

In this paper, we employed a case study to assess the performance of e-payment systems in Ghana. A case study is an appropriate method because it helps to explore the problem in its natural situation [13]. To evaluate e-payment systems performance in Ghana, an expert view approach was used. First and foremost, a prior data were collected from 300 university students who are users of the e-payment systems across the country for this study. The selection of these students was purposive and based on conversance with the e-payment domain and the ability to offer a vast spectrum experience in the field. Moreover, a respondent had to demonstrate an indepth knowledge of e-payment technology and their applications. A questionnaire was used to ascertain responses from the respondents regarding the performance of the e-payment systems. Based on the data gathered, a team of five experts from academia and the financial industry were invited to help in the evaluation process. From the survey, a pairwise comparison of the criteria and a decision matrix for evaluating the e-payment systems were constructed. These served as input for the AHP and the probability linguistic TOPSIS method.

\subsection{Results Analysis}

In accordance with the objective of this research, the alternatives were evaluated with each of the related criteria. Based on this, a hierarchy diagram was developed, as shown in Figure 1. 


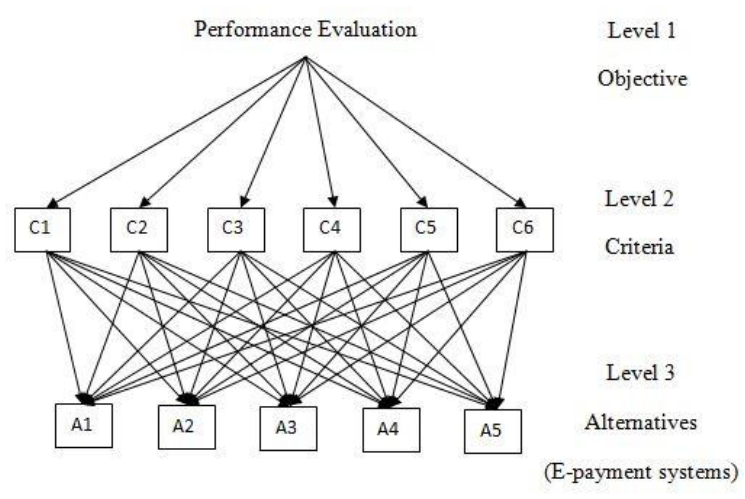

Figure. 1. The Hierarchy structure of the e-payment systems' evaluation problem

Figure 1 shows the objective criteria and alternatives in the order of their linkage. We employed the AHP procedure outlined in subsection 3.1 to obtain the weights of the criteria. Based on the responses from the respondents, the team of experts constructed a pairwise comparison matrix by using the Saaty's 1-9 scale; see Table 1, to compare the various criteria. The result is shown in Table 4.

Table 3. Par-wise comparison matrix for the criteria

\begin{tabular}{|l|l|l|l|l|l|l|}
\hline Criteria & $c_{1}$ & $c_{2}$ & $c_{3}$ & $c_{4}$ & $c_{5}$ & $c_{6}$ \\
\hline$c_{1}$ & 1.00 & 0.17 & 0.20 & 0.50 & 0.25 & 0.11 \\
\hline$c_{2}$ & 6.00 & 1.00 & 2.00 & 5.00 & 3.00 & 0.25 \\
\hline$c_{3}$ & 5.00 & 0.50 & 1.00 & 7.00 & 3.00 & 0.25 \\
\hline$c_{4}$ & 2.00 & 0.20 & 0.14 & 1.00 & 0.25 & 0.11 \\
\hline$c_{5}$ & 4.00 & 0.33 & 0.33 & 4.00 & 1.00 & 0.14 \\
\hline$c_{6}$ & 9.00 & 4.00 & 4.00 & 9.00 & 7.00 & 1.00 \\
\hline
\end{tabular}

The goal of the comparison was to ascertain the weights of the criteria for the ranking of the alternatives and also to find out the contributing factor for e-payment adoption. The consistency ratio of the comparison matrix for the criteria was found to be 6.1 , which is less than the threshold $10 \%$. Hence, we can conclude that there is no inconsistency in the decision matrix. The results obtained from the AHP method is presented in Figure 2. 


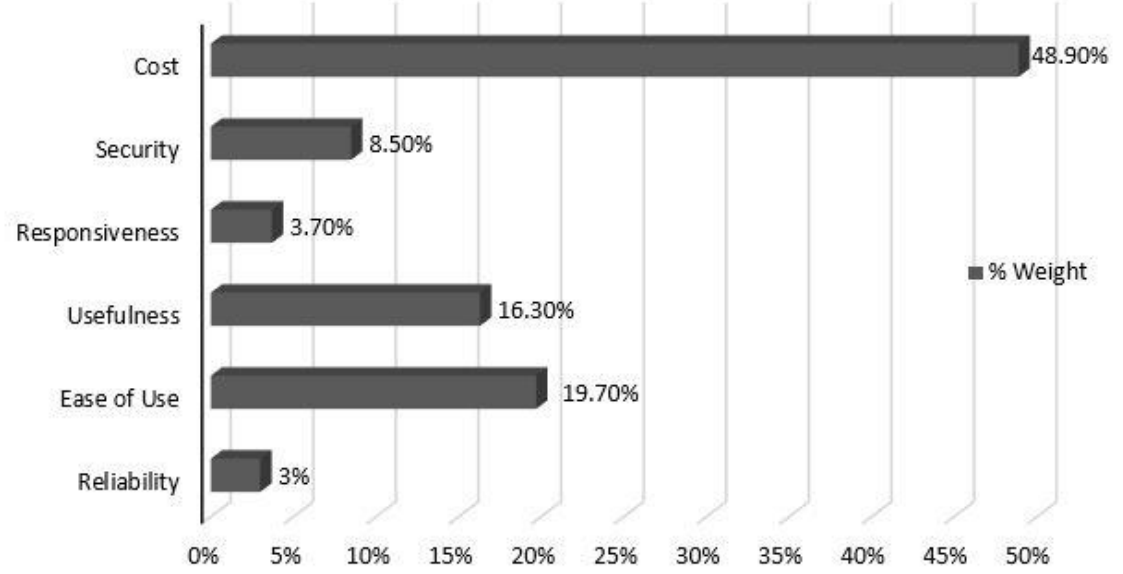

Figure. 2. Percentage contribution of each criterion to e-payment systems' performance

Figure 2 shows the contribution of each criterion to the performance of e-payment systems in Ghana. It is obvious from figure 2 that cost with the weight of $48.9 \%$ is the main contributor to epayment systems usage and performance. The least contributor to e-payment systems usage and performance is reliability with a weight of $3 \%$.

Thereafter, a probabilistic linguistic decision matrix was formed by comparing each alternative with the criteria. Firstly, a probabilistic linguistic value, ranging from fair to extremely important, was assigned to each alternative based on its performance with each criterion. The normalized integrated decision matrix provided by the team of experts is shown in Table 5.

Table 4. Normalized probabilistic decision matrix provided by the experts.

\begin{tabular}{|c|c|c|c|c|}
\hline & $c_{1}$ & $c_{2}$ & & $c_{3}$ \\
\hline$x_{1}$ & $\left\{\mathrm{~s}_{4}(0.67), \mathrm{s}_{2}(0.33), \mathrm{s}_{2}(0)\right\}$ & $\begin{array}{l}\left\{\mathrm{s}_{5}(0.33)\right. \\
\left.\mathrm{s}_{3}(0.33)\right\}\end{array}$ & $\mathrm{S}_{4}(0.33)$ & $\left\{\mathrm{s}_{4}(0.33), \mathrm{s}_{3}(0.33), \mathrm{s}_{1}(0.33)\right\}$ \\
\hline$x_{2}$ & $\begin{array}{ll}\left\{\mathrm{s}_{5}(0.33),\right. & \mathrm{s}_{3}(0.33), \\
\left.\mathrm{s}_{1}(0.33)\right\} & \\
\end{array}$ & $\begin{array}{l}\left\{\mathrm{s}_{3}(0.67)\right. \\
\left.\mathrm{s}_{3}(0)\right\}\end{array}$ & $\mathrm{s}_{5}(0.33)$ & $\left\{\mathrm{s}_{3}(0.67), \mathrm{s}_{1}(0.33), \mathrm{s}_{1}(0)\right\}$ \\
\hline$x_{3}$ & $\left\{\mathrm{~s}_{2}(1), \mathrm{s}_{2}(0), \mathrm{s}_{2}(0)\right\}$ & $\begin{array}{l}\left\{\mathrm{s}_{3}(0.33)\right. \\
\left.\mathrm{s}_{1}(0)\right\}\end{array}$ & $\mathrm{s}_{1}(0.67)$ & $\left\{\mathrm{s}_{5}(0.33), \mathrm{s}_{2}(0.33), \mathrm{s}_{1}(0.33)\right\}$ \\
\hline$x_{4}$ & $\left\{\mathrm{~s}_{1}(1), \mathrm{s}_{1}(0), \mathrm{s}_{1}(0)\right\}$ & $\begin{array}{l}\left\{\mathrm{s}_{2}(0.67),\right. \\
\left.\mathrm{s}_{1}(0)\right\}\end{array}$ & $\mathrm{s}_{1}(0.33)$ & $\left\{\mathrm{s}_{2}(0.67), \mathrm{s}_{1}(0.33), \mathrm{s}_{1}(0)\right\}$ \\
\hline \multirow[t]{2}{*}{$x_{5}$} & $\begin{array}{l}\left\{\mathrm{s}_{5}(0.33)\right. \\
\left.\mathrm{s}_{4}(0.33)\right\}\end{array}$ & $\begin{array}{l}\left\{\mathrm{s}_{4}(0.67),\right. \\
\left.\mathrm{s}_{3}(0)\right\}\end{array}$ & $\mathrm{s}_{3}(0.33)$ & $\left\{\mathrm{s}_{5}(0.33), \mathrm{s}_{4}(0.33), \mathrm{s}_{3}(0.33)\right\}$ \\
\hline & $c_{4}$ & $c_{5}$ & & $c_{6}$ \\
\hline$x_{1}$ & $\begin{array}{l}\left\{\mathrm{s}_{4}(0.33)\right. \\
\left.\mathrm{s}_{2}(0.33)\right\}\end{array}$ & $\begin{array}{l}\left\{\mathrm{s}_{5}(0.67),\right. \\
\left.\mathrm{s}_{2}(0)\right\}\end{array}$ & $\mathrm{s}_{2}(0.33)$, & $\left\{\mathrm{s}_{4}(0.33), \mathrm{s}_{3}(0.33), \mathrm{s}_{1}(0.33)\right\}$ \\
\hline$x_{2}$ & $\begin{array}{ll}\left\{\mathrm{s}_{5}(0.33),\right. & \mathrm{s}_{3}(0.33), \\
\left.\mathrm{s}_{2}(0.33)\right\} & \\
\end{array}$ & $\begin{array}{l}\left\{\mathrm{s}_{3}(0.33)\right. \\
\left.\mathrm{s}_{1}(0.33)\right\}\end{array}$ & $\mathrm{s}_{2}(0.33)$, & $\left\{\mathrm{s}_{5}(0.33), \mathrm{s}_{4}(0.33), \mathrm{s}_{2}(0.33)\right\}$ \\
\hline$x_{3}$ & $\left\{\mathrm{~s}_{2}(0.67), \mathrm{s}_{1}(0.33), \mathrm{s}_{1}(0)\right\}$ & $\begin{array}{l}\left\{\mathrm{s}_{2}(0.67)\right. \\
\left.\mathrm{s}_{2}(0)\right\}\end{array}$ & $\mathrm{s}_{4}(0.33)$ & $\left\{\mathrm{s}_{3}(0.67), \mathrm{s}_{5}(0.33), \mathrm{s}_{3}(0)\right\}$ \\
\hline$x_{4}$ & $\left\{\mathrm{~s}_{2}(0.67), \mathrm{s}_{1}(0.33), \mathrm{s}_{1}(0)\right\}$ & $\begin{array}{l}\left\{\mathrm{s}_{2}(0.67),\right. \\
\left.\mathrm{s}_{2}(0)\right\}\end{array}$ & $\mathrm{s}_{3}(0.33)$ & $\left\{\mathrm{s}_{5}(0.33), \mathrm{s}_{2}(0.67), \mathrm{s}_{2}(0)\right\}$ \\
\hline$x_{5}$ & $\begin{array}{l}\left\{\mathrm{s}_{5}(0.33)\right. \\
\left.\mathrm{s}_{3}(0.33)\right\}\end{array}$ & $\begin{array}{l}\left\{\mathrm{s}_{4}(0.33)\right. \\
\left.\mathrm{s}_{1}(0.33)\right\}\end{array}$ & $\mathrm{s}_{2}(0.33)$ & $\left\{\mathrm{s}_{4}(0.67), \mathrm{s}_{2}(0.33), \mathrm{s}_{2}(0)\right\}$ \\
\hline
\end{tabular}


Based on the result of Table 5, the probabilistic linguistic-TOPSIS approach, as described in subsection 3.2, was used to ascertain the performance scores of the e-payment systems and hence, ranks were calculated. The e-payment system with the highest TOPSIS index (performance score) was given the highest rank. The results are exhibited in Table 6.

Table 5. Performance scores and corresponding ranks

\begin{tabular}{|l|l|l|}
\hline E-payment systems & $\begin{array}{l}\text { Performance } \\
\text { score }\end{array}$ & Performance Rank \\
\hline ATM & -0.5001 & 3 \\
\hline Mobile Money & -0.4162 & 2 \\
\hline Online Banking & -0.6495 & 4 \\
\hline E-Zwich & -1.0831 & 5 \\
\hline Credit (Debit) card & 0 & 1 \\
\hline
\end{tabular}

Based on Table 6, the performance of the e-payment systems is arranged in descending order as follows: Credit (Debit) Card > Mobile Money > ATM > Online Banking > E-zwich. It is evident that Credit (Debit) cards are the best- performing e-payment system in Ghana, and E-zwich is the least performed one.

\section{Discussion and Evaluation}

\subsection{Discussion}

Cost-effectiveness ranks higher amongst Ghanaians in rating performance of e-payment system. Based on the rankings of criteria for this investigation, the performance of an e-payment system is estimated to be about forty-nine percent (48.9\%) dependant on the cost borne by its users. This revelation suggests that for e-payment to triumph in the country's business landscape, providers of such services should devote much attention to beat down the transaction cost. Another determinant of e payment performance is its ease of use. It is observed that about twenty percent (19.7\%) of an e-payments satisfactory performance to customers hinges on its operational simplicity. The weight garnered by the ease of use in this study indicates that users expect the electronic payment systems to be less demanding but rather easy to navigate around them within a shortest possible time. This observation is in alignment with the proposition of the TAM model, which argues that the easier to operate a new technological innovation, the better for people to adopt the technology. This suggests that most Ghanaians are concerned about the technical skills required to operate these payment channels. Hence, users satisfaction depend partly on the ease of use.

Usefulness of the particular electronic payment outlet was ranked third out of the six criteria employed in this study. The performance of the various e-payment systems in Ghana is about sixteen percent $(16.3 \%)$ based on their usefulness. This position of the criterion "usefulness" presupposes that in the performance metric of the e-payment system in Ghana, how useful the payment mode is, contributes $16 \%$ to its total performance rating. The security of a payment system was registered at the fourth position on the ranking scale. Only $8.5 \%$ of the total performance rating comes from the security of an e-payment system in Ghana. This indicates that cost, ease of use, and usefulness are prioritized ahead of security in relation to e-payment technology. The responsiveness and reliability of an e-payment system are the least contributors to the total performance rating of the e-payment system. Just about $3.7 \%$ is contributed by responsiveness, while reliability accounts for $3.0 \%$. 
Credit/Debit card is the most preferred e-payment channel, followed by Mobile Money. ATM, online banking, and E-zwich occupied the third to fifth position, respectively. This can be attributed to the transaction cost involved and its operational convenience. A debit/ credit card can be used for different transactions and at different point of sales (POS) available to customers. The Ghanaian user makes payment at the restaurants and supermarkets and pays most bills with their credit/debit card. Next to credit/debit card is mobile money payment system. This is likely to be as a result of the increasing rate of mobile phone penetration in Ghana. Dasmani [53] reported that Ghana's mobile phone penetration rate reached over 35 million in December 2015. Mobile money is used for payment of utility bills payments in merchant shops [7]. For mobile money to catch up with credit/debit card, it is important to strengthen its security and also reduce the transactional costs. Despite the introduction of gh-link in 2011, which enables any local ATM card to be used in all ATM machines in Ghana; this payment system is ranked third. With the increasing population of Ghana, the few gh-link ATMs are inadequate to cater to the demanding needs of customers. In order to reduce this, the GhIPSS has introduced gh-link Hybrid ATMs that accept local ATM cards, e-zwich cards, as well as Visa or MasterCard, depending on the issuing bank. Our results show that Ghanaians customers don't like online banking. This is because of the complexities of websites of banks in Ghana [10]. Most of these websites are not user-friendly, and customers find it difficult to understand. Moreover, Ghanaians customers seem to have developed an unchanging attitude for physical cash transactions as against non-cash transactions. E-zwich is ranked fifth, suggesting that there are lots of challenges associated with the use of ezwich, and hence, customers feel insecure using this payment channel. These challenges are not limited to network failures and frequent breakdown of machines but also a slow process of service delivery and long queues, defects with regards to customers' cards due to improper handling, and low benefits to banks as a result of banks operating the service on behalf of GhIPSS [22]. E-zwich could be a saviour to the long queue in Ghanaian banking halls, and hence all stakeholders should endeavour to make this system stand and not become like some systems like SG-SSB and Sika card which could not stand the test of time in Ghana.

\subsection{Implication}

The insightful revelations of this study suggest a policy overhaul and institutional and structural changes within Ghana's payment landscape. Firstly, additional investment in e-payment infrastructure should be encouraged to enhance efficiency and accessibility. Most importantly, investments should target further reduction of operational cost to motivate people to subscribe to the e-payment systems.

Secondly, the results imply that government's overriding focus on e-payment expansion is a misplaced priority. This calls for attention to improving the foundation of e-payment system while creating an enabling environment for the attainment of cashlite society. Challenges related to E-Zwich such as frequent breakdown of the machines, erratic power supply and unavailability of POS at vantage points around the country as evidenced in the studies of [10] must be addressed with utmost urgency to spur this e-payment method to life again. Thirdly, mass sensitization of the inherent economic benefits of e- payment policies must be rolled out by government agencies and other stakeholders.

The results of this study also imply that industry players within the financial administration sectors in Ghana are a bit distant from the customers; hence, customer's expectation may run counter with what service providers offer. This means that there should be customer engagement at regular intervals to incorporate their ideas in the provision of e-payment services. Again, the design of the technology involved in e-payment transactions must be simple to enable people with a basic understanding of ICT to be able to operate with ease. 


\section{Conclusion}

The contributions of e-payment systems to the national economic fortunes are widely acknowledged by economists, governments, and the business communities. We assessed the performance of e-payment systems in Ghana in order to make proactive insights into the epayment systems policy. We employed an integration method of AHP and probabilistic linguistic TOPSIS methods to ascertain the performance scores of the various e-payment systems. The results showed that cost effectiveness is the major factor consumers consider when choosing an epayment system. This is followed by ease of use, usefulness, security, responsiveness and reliability, respectively. In the evaluation performance of the e-payment systems, the results indicated that credit/debit card has the highest performance score, followed by mobile money, ATM, online banking, and E-zwich, respectively.

Even though this study's contributions to the improvement of the performance of e-payment systems in Ghana cannot be underestimated, it is however suggested that future studies address certain factors which might have affected these findings. We recommend that further studies should consider enlarging the sample size by gathering responses from across the length and breadth of the country. Also, other e-payment methods which were not included in this study should be roped in to ascertain their effect on the results. Lastly, future studies should evaluate the actual or average margin of e-payment systems performance improvement using the improved infrastructural base as a moderating variable.

\section{ACKNOWLEDGEMENTS}

The authors would like to express their gratitude to the usable answers of survey respondents and valuable comments of the anonymous reviewers.

\section{REFERENCE}

[1] Slozko, O. \& Pelo, A., (2015). Problems and risks of digital technologies introduction into epayments. Transformations in Business and Economics. 14 (1) 42-59.

[2] Barkhordari, M., Nourollah, Z., Mashayekhi, H., Mashayekhi, Y., Ahangar, M.S., (2017). Factors influencing adoption of e-payment systems: an empirical study on Iranian customers. Information Systems and e-Business Management, 15(1), 89-116.

[3] Deningtyas, F., \& Ariyanti, M., (2017). Factors Affecting the Adoption of E-Payment on Transportation Service Application Using Modified Unified Technology of Acceptance and Use of Technology 2 Model. Proceedings of Academics World 64th International Conference, Putrajaya, Malaysia, (3), 38-43.

[4] Fernandes, L., (2013). Fraud in electronic payment transactions: Threat and countermeasures, Asia Pacific Journal of Marketing and Management Review, 2 (3), 23-32.

[5] Kovács, L., David, S., (2016). Fraud risk in electronic payment transactions. Journal of Money Laundering Control. https://doi.org/10.1108/jmlc-09-2015-0039.

[6] Tee, H.H. \& Ong, H.B., (2016). Cashless payment and economic growth. Financial Innovation. https://doi.org/10.1186/s40854-016-0023-z.

[7] KPMG, (2016). Payment Developments in Africa, The payments Journey. [online]. Available: www.blog.kpmgafrica.com/payment-developments-in-africa-2016-vol-1. 
[8] Awiagah, R., Kang, J. \& Lim, J.I., (2016). Factors affecting e-commerce adoption among SMEs in Ghana. Information Development. https://doi.org/10.1177/0266666915571427.

[9] Crabbe, M., Standing, C., Standing, S. \& Karjaluoto, H., (2009). An adoption model for mobile banking in Ghana. International Journal of Mobile Communications. https://doi.org/10.1504/ijmc.2009.024391.

[10] Issahaku, H., (2012). Challenges of electronic payment systems in Ghana: The case of e-ZWICH. American Journal of Business and Management. 1, 87-95.

[11] Shafie, I. S. M., Yusof, Y. L. M., Mahmood, A. N., Ishar, N. I. M., Jamal, H. Z., \& Kasim, N. H. A. A. , (2018). Factors Influencing the Adoption of E-Payment: An Empirical Study in Malaysia. Advances in Business Research International Journal, 53-62.

[12] Antwi, S.K., 2016. Examining the effectiveness of electronic payment system in Ghana: The case of e-ZWICH in the Tamale Metropolis. Research Journal of Finance and Accounting. Available: www.iiste.org.

[13] Komlan, G., Koffi, D. \& Kingsford, K.M., (2016). MCDM Technique to evaluating mobile banking adoption in the Togolese banking industry based on the perceived value: Perceived benefit and perceived sacrifice factors. International Journal of Data Mining \& Knowledge Management Process. https://doi.org/10.5121/ijdkp.2016.6304.

[14] Liang, D., Pedrycz, W., Liu, D. \& Hu, P., (2015). Three-way decisions based on decision-theoretic rough sets under linguistic assessment with the aid of group decision making. Applied Soft Computing Journal 29, 256-269. https://doi.org/10.1016/j.asoc.2015.01.008.

[15] Chen, C.T., Lin, C.T. \& Huang, S.F., (2006). A fuzzy approach for supplier evaluation and selection in supply chain management. International Journal of Production Economics. https://doi.org/10.1016/j.ijpe.2005.03.009.

[16] Zhang, X., (2016). A novel approach based on similarity measure for Pythagorean fuzzy multiple criteria group decision making. International Journal of Intelligent Systems. https://doi.org/10.1002/int.21796.

[17] Zadeh, L.A., (1965). Fuzzy sets. Information and Control, 8 (3), 338-353.

[18] Saaty, R.W., (1980). The Analytic Hierarchy Process., McGraw-Hill, New York.

[19] Pang, Q., Wang, H., Xu, Z., (2016). Probabilistic linguistic term sets in multi-attribute group decision making. Information Sciences 369, 128-143. https://doi.org/10.1016/j.ins.2016.06.021

[20] Ametepe, M.I.T., Abdullai, W.D. \& Annan, N.K., ( 2015). Examining issues of electronic payment systems in Ghana, 5, 7-14.

[21] Mubarik, A., (2016). BoG gives approval for mobile money users to earn interest on deposit. [Online]. Available: http://www.pulse.com.gh/news/business/mobile-money-in-ghana-transactionbog-gives-approval-for-mobile-money-users-to-earn-interest-on-deposit-id5438159.html.

[22] GhIPSS, (2017). Ghana Interbanks Payment Structure to introduce instant interbank payment system. [Online]. Available: website (http://www.ghipss.net).

[23] Perkins, E.-Z.D. \& Annan, J., (2013). Factors affecting the Adoption of Online Banking in Ghana: Implications for Bank Managers. International Journal of Business and Social Research.

[24] Ofori-Boateng, P., (2017). Internet banking is unpopular in Ghana. Available: https://www.ghanabusinessnews.com/2017/05/02/internet-banking-is-unpopular-in-ghana/ 
[25] Szopiński, T.S., (2016). Factors affecting the adoption of online banking in Poland. Journal of Business Research. https://doi.org/10.1016/j.jbusres.2016.04.027.

[26] Woldie, A., Hinson, R., Iddrisu, H. \& Boateng, R., (2008). Internet banking: an initial look at Ghanaian bank consumer perceptions. Banks and Bank Sytems. 3 (3), 35-46.

[27] Marcia, C., (2010). Consumer behaviour drives innovation in ATM technology. [Online]. NCR Corporation, Available: http://www.atmmarketplace.com.

[28] Rutherford, L. \& DeVaney, S.A., (2009). Utilizing the theory of planned behavior to understand convenience use of credit cards. Journal of Financial Counseling and Planning.

[29] Gharaibeh, A.M.O. \& Qader, A.A.A.A., (2017). Factors influencing firm value as measured by the Tobin's Q: Empirical evidence from the Saudi Stock Exchange (TADAWUL). International Journal of Applied Business and Economic Research 15, 333-358.

[30] Breckenridge, K., (2010). The world's first biometric money: Ghana's E-Zwich and the contemporary influence of South African biometrics. Journal of the International African Institute, 80 (4), 642-662https://doi.org/10.3366/afr.2010.0406.

[31] Zokaee, S., Ebrahimi, S.B. \& Ghazizadeh, M., (2012). Electronic Payment Systems Evaluation: A Case Study in Iran. Information Management \& Business Review, 4, 120-127.

[32] Osmani, M., Moradi, K., Rozan, M.Z.A. \& Layegh, M.A., (2017). Using AHP method to evaluate epayment system factors influencing mobile banking use in Iranian banks. International Journal of Business Information Systems. https://doi.org/10.1504/ijbis.2017.082897.

[33] Alptekin, G. \& Alptekin, S.E., (2010). Evaluation of electronic payment systems using fuzzy multicriteria decision making approach 4, 791-796.

[34] Hu, Y.C. \& Liao, P.C., (2011). Finding critical criteria of evaluating electronic service quality of Internet banking using fuzzy multiple-criteria decision making. Applied Soft Computing Journal. https://doi.org/10.1016/j.asoc.2011.02.008.

[35] Zeithaml, V.A., Parasuraman, A. \& Malhotra, A., (2000). A Conceptual framework for understanding e-service quality: Implications for future research and managerial Practice. Marketing Science Institute. https://doi.org/10.1177/1094670504271156.

[36] Sanghita Roy, D.I.S., (2014). Determinants of customers' acceptance of electronic payment system in Indian banking sector - A study. International Journal of Scientific \& Engineering Research. 5 (1), 177-186.

[37] Lubanga, J. M. , Gakobo, T., Ochieng, I. \& Kimando, L. N., (2017). Factors Influencing Adoption of E-Payment System in Kenyan Public Transport: a Case of Matatu Plying Nairobi-Kitengela Route. International Academic Journal of Human Resource and Business Administration, 2 (4), 27-48.

[38] Abrazhevich, D., (2001). Classification and characteristics of electronic payment systems, in: Lecture Notes in Computer Science (Including Subseries Lecture Notes in Artificial Intelligence and Lecture Notes in Bioinformatics). https://doi.org/10.1007/3-540-44700-8_8.

[39] Pant, S., (2011). A secure online payment system. Theses and Dissertation-Computer Science, 1. https//uknowledge.uky.edu/cs_etds/1.

[40] Bezhovski, Z., (2016). The Future of the mobile payment as electronic payment system. European Journal of Business and Management 8(8), 127-132.

[41] Worku, G., (2010). Electronic-banking in Ethiopia- practices, opportunities and challenges. Journal of Internet Banking and Commerce, 15(2). 
International Journal of Data Mining \& Knowledge Management Process (IJDKP) Vol.9, No.2/3, May 2019

[42] Alharbi, S. \& Naderpour, M., (2016). E-commerce development risk evaluation using MCDM techniques. Lecture Notes in Business Information Processing 250, 88-99. https://doi.org/10.1007/978-3-319-32877-5_7.

[43] Valimaki, C., (2017). The growing giant: Managing R\&D in China https://www.manufacturingglobal.com/leadership/growing-giant-managing-rd-china.

[44] Chen, C.T., Lin, C.T. \& Huang, S.F., (2006). A fuzzy approach for supplier evaluation and selection in supply chain management. International Journal of Production Economics. https://doi.org/10.1016/j.ijpe.2005.03.009.

[45] Yoo, K.E. \& Choi, Y.C., (2006). Analytic hierarchy process approach for identifying relative importance of factors to improve passenger security checks at airports. Journal of Air Transport Management. https://doi.org/10.1016/j.jairtraman.2005.11.006.

[46] Görener, A., Toker, K. \& Uluçay, K., (2012). Application of combined SWOT and AHP: A Case study for a manufacturing firm. Procedia - Social and Behavioral Sciences. https://doi.org/10.1016/j.sbspro.2012.09.1139.

[47] Chang, D.Y., 1996. Applications of the extent analysis method on fuzzy AHP. European Journal of Operational Research. https://doi.org/10.1016/0377-2217(95)00300-2.

[48] Yoon, K. \& Hwang, C.L., (1985). Manufacturing plant location analysis by multiple attribute decision making: Part isingle plant strategy. International Journal of Production Research. https://doi.org/10.1080/00207548508904712.

[49] Karim, R. \& Karmaker, C.L., (2016). Machine selection by AHP and TOPSIS Methods. American Journal of Industrial Engineering. https://doi.org/10.12691/ajie-4-1-2.

[50] Wang, T.C. \& Chen, Y.H., (2007). Applying consistent fuzzy preference relations to partnership selection. Omega. https://doi.org/10.1016/j.omega.2005.07.007.

[51] Wang, Y.M. \& Elhag, T.M.S., (2006). Fuzzy TOPSIS method based on alpha level sets with an application to bridge risk assessment. Expert Systems with Applications. https://doi.org/10.1016/j.eswa.2005.09.040.

[52] Pang, Q., Wang, H. \& Xu, Z., (2016). Probabilistic linguistic term sets in multi-attribute group decision making. Information Sciences 369, 128-143. https://doi.org/10.1016/j.ins.2016.06.021

[53] Dasmani Laary, (2016). Mobile phone penetration soars to 128\%. [Online]. Available: http://www.theafricareport.com/West-Africa/ghana-mobile-phone-penetration-soars-to-128.html 


\section{Authors}

Dennis Asante is a researcher and Public policy expert. His research interests span across e-governance policies, public health policies, and environmental governance. $\mathrm{He}$ is currently affiliated with School of Management and Economics, University of Electronic Science and Technology of China as a Ph.D. candidate. You may contact him through: Email: denniyoung94@yahoo.com

Evans Opoku-Mensah is a Ph.D researcher at the University of Electronic Science and Technology of China. He specializes in research and development investments, stock price and merger and acquisition. You may contact him through: Email: evans@std.uestc.educn/ evamens2@yahoo.com.

Peter Adjei Darko is a researcher at the University of Electronic Science and Technology of China. His research interest includes decision making under uncertainty, information aggregation, and their application in e-business and health. You may contact him through: Email: paadarko@yahoo.com
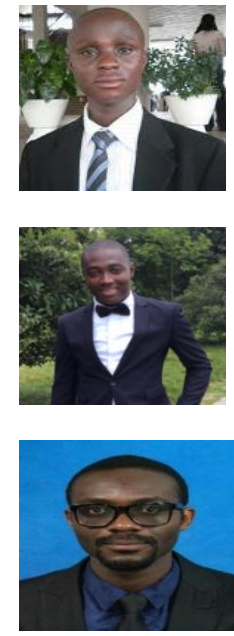